\title{
Follistatin, a Novel Biomarker for Malignant Gliomas
}

\author{
Elvira Lekka1 ${ }^{*}$, Nicolas Tsesmetzis' ${ }^{2}$ Katherine M. Ashton ${ }^{3}$, Peter Abel ${ }^{4}$, Charles Davies ${ }^{1}$, \\ Gregory Hall ${ }^{1}$, Timothy Dawson ${ }^{3}$, Robert W. Lea ${ }^{4}$ \\ ${ }^{1}$ Department of Neurosurgery, Lancashire Teaching Hospitals NHS Trust, Royal Preston Hospital, Preston, UK \\ ${ }^{2}$ Faculty of Life Sciences, University of Manchester, Manchester, UK \\ ${ }^{3}$ Department of Pathology, Lancashire Teaching Hospitals NHS Trust, Royal Preston Hospital, Preston, UK \\ ${ }^{4}$ School of Pharmacy and Biomedical Sciences, University of Central Lancashire, Preston, UK \\ Email: ${ }^{*}$ elvira.lekka@srft.nhs.uk
}

Received 29 June 2015; accepted 5 September 2015; published 8 September 2015

Copyright (C) 2015 by authors and Scientific Research Publishing Inc.

This work is licensed under the Creative Commons Attribution International License (CC BY).

http://creativecommons.org/licenses/by/4.0/

(c) (i) Open Access

\begin{abstract}
Molecular biomarkers are commonly used for the management of several types of malignant tumours in routine clinical practice. However, this is not the case for malignant gliomas. Cytokines and Angiogenesis factors are potential candidates due to their intrinsic role in tumourigenesis. Pre- and post-operative serum from 36 malignant glioma patients and 36 controls was analysed using the Bio-Plex Pro Angiogenesis and Cytokines Assay (Bio-Rad, USA). Amongst the molecules tested, the serum concentration of follistatin was significantly higher in patients than in controls. Moreover, the serum concentration of follistatin of the patients postoperatively was significantly reduced compared to that preoperatively. Factors such as age and gender did not affect the concentrations of follistatin measured in the serum of patients pre- and post-operatively as well as healthy controls. This is the first report of follistatin as potential biomarker for the detection of malignant gliomas.
\end{abstract}

\section{Keywords}

Serum, Malignant Gliomas, Follistatin, Biomarker, Cancer

\section{Introduction}

A biomarker is a measurable substance, which can be used to indicate a biological state. Such state can be a normal biological process, a disease or even a pharmacological response to treatment. Examples of commonly used biomarkers include Glycated Haemoglobin $\left(\mathrm{Hb}_{1} \mathrm{Ac}\right)$ for diabetes mellitus, blood pressure monitoring in

"Corresponding author. 
hypertension, and chromosomal abnormalities in genetic syndromes [1].

Biomarkers are also widely used in the overall management of malignant tumours [2]. They are important aids, as they allow prognostication, early detection of recurrence and monitoring during treatment [2]. They are already used as part of disease monitoring in several common cancers, such as prostate cancer and ovarian cancer, hepatocellular cancer, to name a few [3]-[5].

Gliomas derive from glial cells. These can be ependymomas, deriving from ependymal cells, astrocytomas from astrocytes, oligodendrogliomas from oligodendrocytes and mixed gliomas such as oligoastrocytomas from different types of glial cells. The most common grading system for gliomas is the World Health Organisation (WHO) grading system which classifies gliomas in low grade gliomas (WHO grade I and II) and high grade ones (WHO grade III and IV). This classification takes into account pathological characteristics for each grade. The histopathological hallmarks of high grade gliomas include mitotic activity, cellular pleomorphism, necrosis and microvascular proliferation [6].

The aetiology of malignant gliomas is unknown. They are rarely related to radiation exposure. They can occur sporadically or as part of hereditary syndromes (Li-Fraumeni, NF1 and Turcot). Recent studies of molecular genetics have suggested that glioblastomas may arise by two separate pathways, primary or de novo glioblastoma and secondary glioblastoma. Secondary glioblastomas arise by malignant progression from a low grade glioma whereas de novo glioblastomas arise without a lower grade precursor. The two subtypes of glioblastoma are characterized by different genetic alterations. The de novo glioblastomas frequently have Epidermal Growth Factor Receptor gene amplification (EGFR), overexpression of Mouse Double Minute 2 (MDM2) and Phosphatase and tensin homolog deleted on chromosome 10 (PTEN) mutations whilst the secondary tumours show p53 gene mutations and PDGFR- $\alpha$ (platelet-derived growth factor receptor- $\alpha$ ) overexpression. Glioblastoma multiforme (WHO IV) is the commonest malignant glioma [7] [8].

The clinical presentation of malignant gliomas depends on the site of their origin. They generally cause focal neurological signs, signs of raised intracranial pressure such as headaches, nausea and vomiting as well as seizures.

Malignant gliomas can occur at any age but most commonly after the age of 40 . Their peak incidence is between 65 and 75 years of age [9] [10].

The overall management of malignant gliomas is particularly challenging [11]. They are difficult to diagnose at an early stage as they may not reveal their presence until they have reached a considerable size or have invaded vital areas of the brain. These factors limit the extent of radical treatment that can be offered to the patients affected by these tumours [12]. Brain tumour biomarkers would aid early diagnosis as well as enable clinicians to offer more radical treatment which would lead to better outcomes [12].

In recent years, several studies have identified potential candidate molecules as brain tumour biomarkers but so far very few of them have been used in clinical practice [13]. Amongst the most promising ones for clinical use are the Cytokines and the Angiogenesis factors. Some of these molecules such as vascular endothelial growth factor (VEGF) and platelet-derived growth factor (PDGF) are obvious candidate serum biomarkers for malignant gliomas as they are directly involved in tumour angiogenesis [14]. Less obvious ones are those playing a more peripheral role in tumour proliferation. An example of such a potential biomarker is the glycoprotein follistatin (FLT).

Follistatin is expressed in nearly all tissues [15]-[18]. Its main function is to bind and neutralise Transforming Growth Factor (TGF) [15]-[18]. It has been reported that follistatin suppresses tumour invasion in several malignancies including lung, ovarian and endometrial cancer, as well as oral squamous carcinoma [15]-[18]. Sakamoto and co-workers report that subjects with chronic kidney disease, chronic liver disease, advanced solid cancer as well as haematological malignancies have higher concentrations of FLT than apparently healthy individuals [19]. Several studies report the "normal range" of follistatin, but its concentration varies with different assays used as well as the type of sample (serum vs. plasma) used to make the measurement [20]-[23].

Here we investigate whether an increase in serum follistatin concentration is correlated with the presence of malignant gliomas. Furthermore, we examine the effect of parameters such as the presence of brain tumour, the operative stage, the age and the gender, to the serum concentration of this angiogenesis factor.

\section{Materials and Methods}

\subsection{Ethical Approval}

A protocol for obtaining serum and plasma samples from patients and healthy controls, along with background 
information for the project to be undertaken and consent forms for patients, healthy controls and next of kin were drawn up and submitted to the Cambridgeshire 3 Research Ethics Committee at the National Research Ethics Service, for ethical approval. Ethical permission was duly obtained (REC reference number 09/H0306/ $50)$.

\subsection{Patient Recruitment}

Serum samples were collected from 36 glioma patients and 36 controls immediately pre-operatively and within 24 hours after undergoing operation. All glioma patients were diagnosed with Glioblastoma Multiforme. Control patients were defined as patients treated surgically under a general anaesthetic in Preston's Neurosurgical Unit for benign disease (i.e. degenerative spinal disease such as disc protrusion or ligamentous thickening), with no past medical history including no known malignancy. None of the controls were on regular medications and in particular steroids of any form. Unlike the controls, glioma patients were administered Dexamethasone in high dose $(16 \mathrm{mg} / \mathrm{day})$. The serum concentration of follistatin was measured using a Bio-Plex Pro Angiogenesis and Cytokines Assay (Bio-Rad, USA) according to the manufacturer's instructions [24].

\subsection{Sample Preparation}

Briefly, serum samples (50 $\mu \mathrm{l}$ per well) or standards (50 $\mu \mathrm{l}$ per well) were incubated with $50 \mu \mathrm{l}$ of the pre-mixed bead sets in pre-wetted 96-well microtiter plates at room temperature for 30 minutes. After washing, $25 \mu l$ of the fluorescent detection antibody mixture was added for $30 \mathrm{~min}$. After washing, $50 \mu \mathrm{l}$ of streptavidin-phycoerythrin was added to each well and $10 \mathrm{~min}$ incubation at room temperature took place. After washing, 125 microliters of assay buffer was added to each well. The plate was shaken at $1100 \mathrm{rpm}$ for $30 \mathrm{sec}$ at room temperature prior to placing it into a plate reader (excitation at $546 \mathrm{~nm}$, emission at $575 \mathrm{~nm}$ ). A range of $3.2-10,000 \mathrm{pg} / \mathrm{mL}$ recombinant full-length follistatin protein was used to establish a standard curve. Follistatin concentrations were determined using a Bio-Plex 200 System (Bio-Rad Laboratories INC, USA). The Bio-Plex Manager software (Bio-Rad Laboratories INC, USA) was used for data acquisition and analysis. The data are reported as relative median fluorescent intensities [25].

\subsection{Data Analysis}

All performed statistical tests were included in the R Statistical package [26]. Outliers were removed using the Fourth-Spread method [27]. Normal distribution of the data was confirmed using a Shapiro-Wilk normality test (p-value 0.05) [28] and statistical significance evaluated using a Student's t-test [29] at a level of $\alpha=0.001$.

\section{Results}

\subsection{Serum Follistatin Concentration Comparison across All Patients and Controls}

The serum concentration of follistatin was significantly higher in glioma patients $(\mathrm{P}<0.001)$ prior to operation $(1133 \pm 279 \mathrm{pg} / \mathrm{ml})$ than after the operation $(86 \pm 44 \mathrm{pg} / \mathrm{ml})$ (Figure 1, Boxplot (a)). Similarly, the preoperative controls had significantly higher serum concentration of follistatin than the postoperative glioma patients (335 \pm 93) (Figure 1, Boxplot (a)). Furthermore, a significant difference was observed in the preoperative serum concentration of follistatin between patients and controls $(\alpha=0.001)$.

The significantly higher serum concentration of Follistatin in the preoperative patients and controls compared to the postoperative patients, as well as between preoperative patients and preoperative controls was also confirmed across all the different age groups tested (i.e. 0 - 39, $40-69$ and $70-100$ of years of age) $(\mathrm{P}<0.001)$ (Figure 1, Boxplots (b)-(d)).

\subsection{Age Group Comparison within the Pre- and the Post-Operative Datasets}

A pairwise comparison of the serum concentration of follistatin was performed between the three age groups in the preoperative, the postoperative and control datasets (i.e. preoperative $0-39$ vs. preoperative $40-69$; preoperative $0-39 v s$. preoperative $70-100$, etc.). This was done in order to investigate whether age plays a role on follistatin's serum concentrations. No significant difference was observed between the different age groups for either the controls, or the patients prior to or after their operation $(\alpha=0.001)$. 


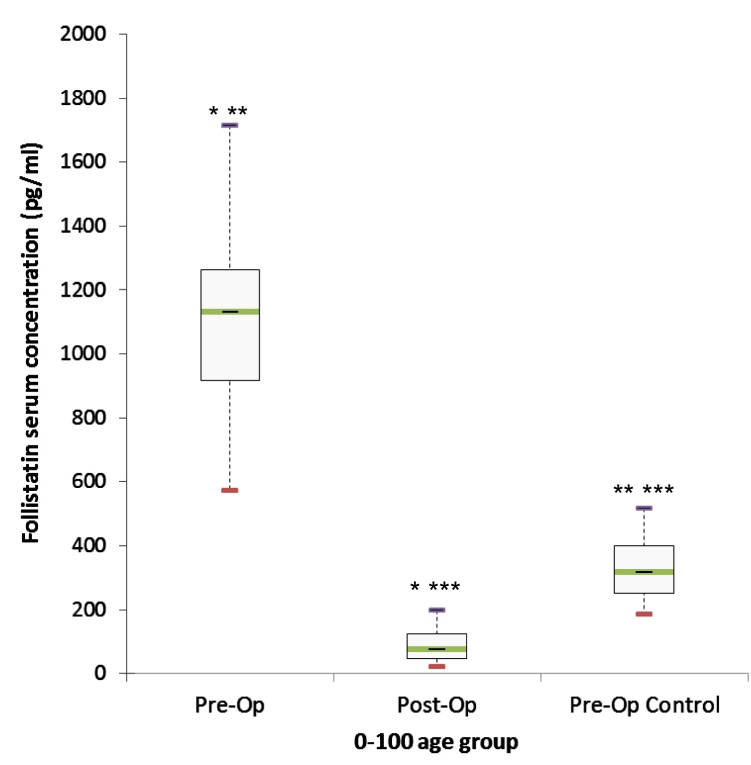

(a)

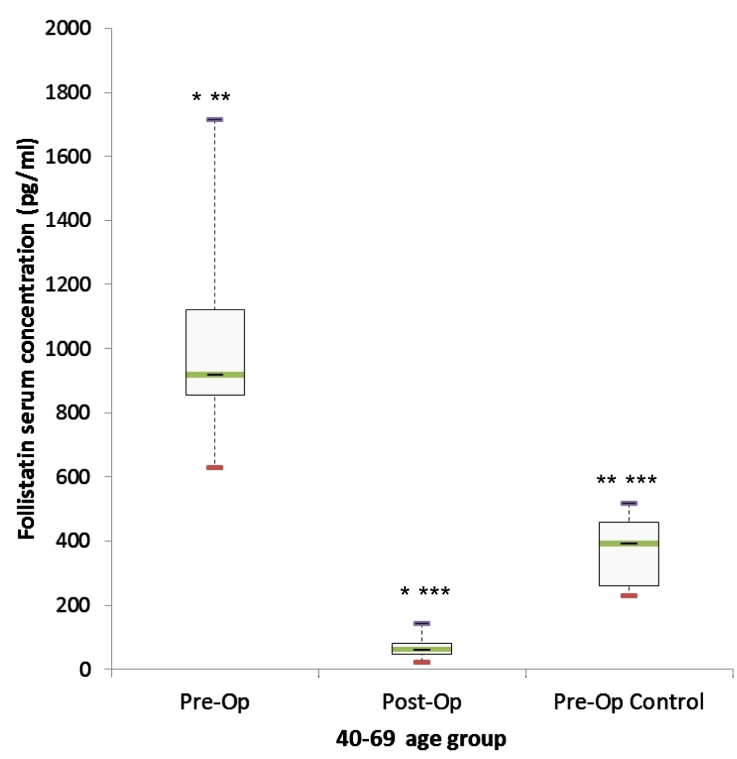

(c)

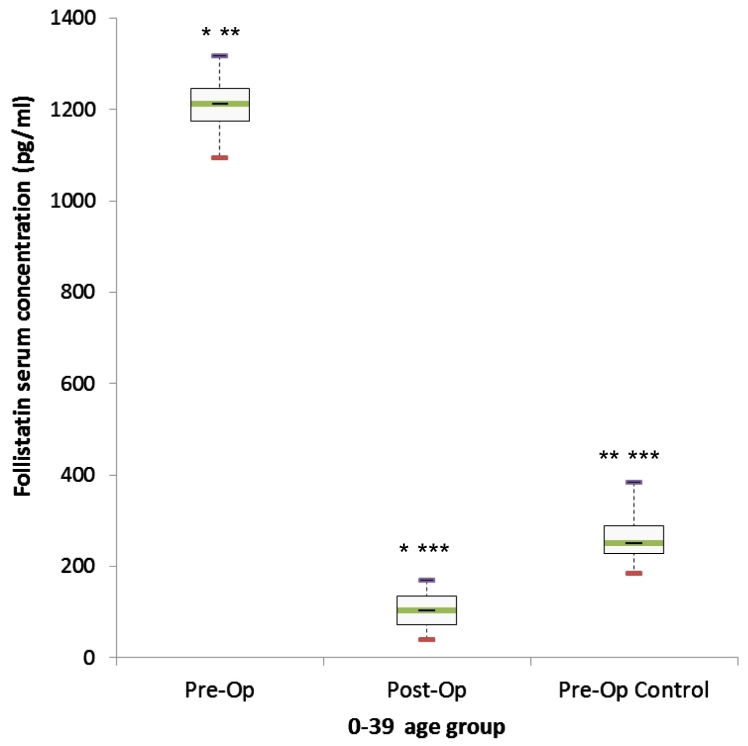

(b)

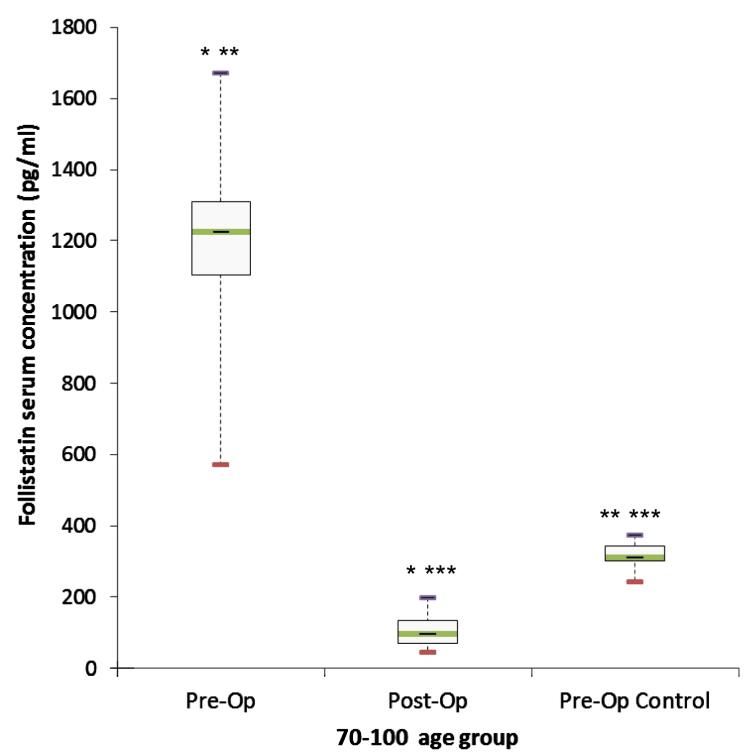

(d)

Figure 1. Boxplots summarizing the preoperative (Pre-Op) and postoperative (Post-Op) serum concentration (pg/ml) of follistatin measured in the malignant glioma patients and controls (Pre-Op Control) across the different age groups 0 - 100 (a), 0 39 (b), 40 - 69 (c), $70-100$ (d). Asterisks $(*)$ indicate pairwisesignificant difference between datasets $(\mathrm{P}<0.001)$.

\subsection{Effect of Gender on Serum Concentration of Follistatin Pre- and Post-0peratively}

The effect of gender on the serum concentration of follistatin pre- and post-operatively as well as between the tumour patients and the controls was examined. The two gender groups did not exhibit any significant difference on the serum concentration $(\mathrm{pg} / \mathrm{ml})$ of follistatin (male preoperative: $1145 \pm 309 v s$. female preoperative: $1114 \pm$ 237; male postoperative: $76 \pm 37 v s$. female postoperative: $100 \pm 51)(\alpha=0.001)$ (Figure 2). Providing that follistatin is indeed a credible biomarker for glioblastomas, this finding suggests that glioblastomas are not preferentially linked to a specific gender. These observations held true regardless of the operative stage (pre- $v s$. post-operative). On the contrary, when the operative stages (pre- $v$ s. post-operative) of glioma patients were compared against each other for each gender separately, both male and female datasets had shown highly significant 


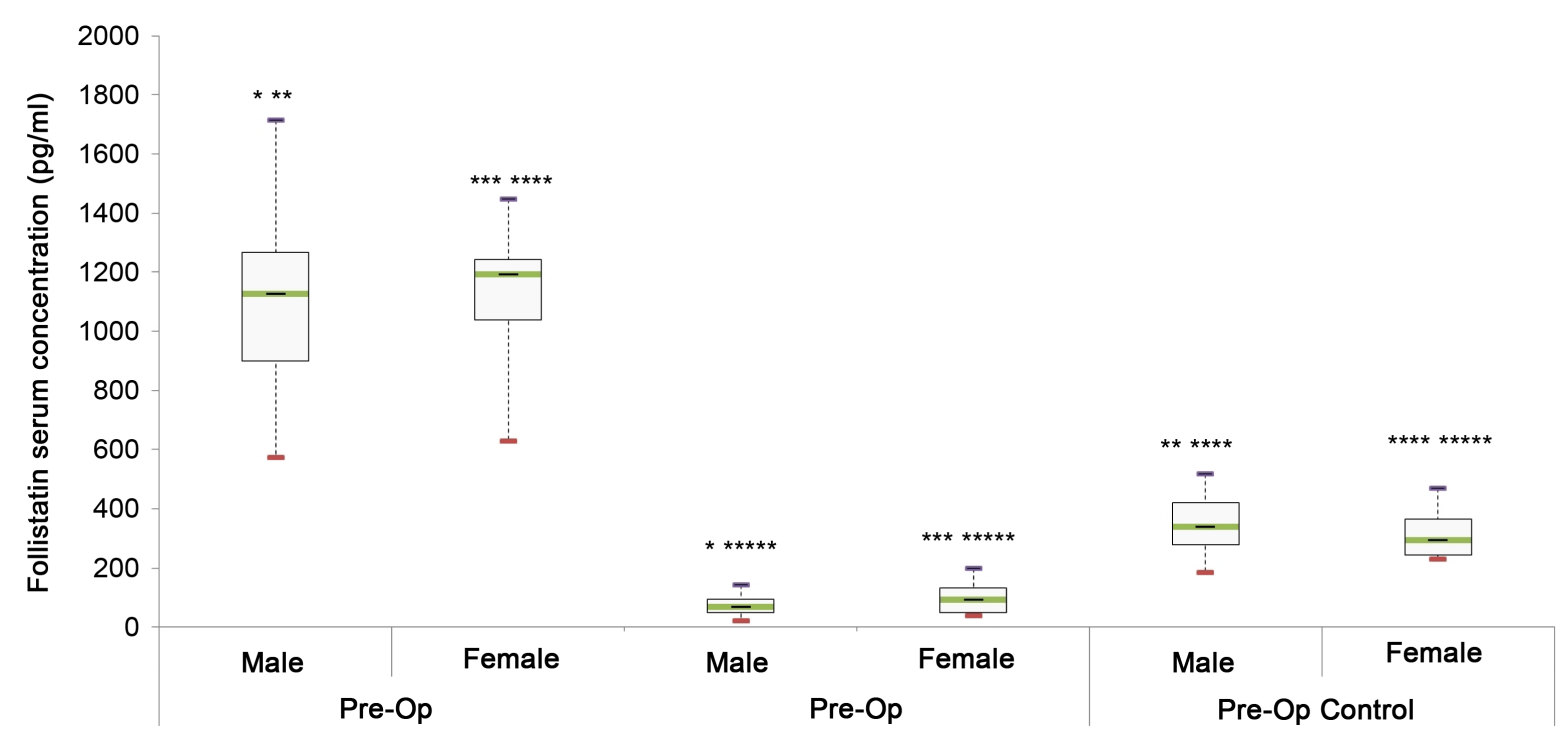

Figure 2. Boxplots summarizing the serum concentration $(\mathrm{pg} / \mathrm{ml})$ of follistatin measured in the male and female malignant patients across all ages pre-operatively, post-operatively, as well as the control patients pre-operatively. Asterisks $\left({ }^{*}\right)$ indicate pairwisesignificant difference between datasets $(\mathrm{P}<0.001)$. In addition, boxplots of the follistatin serum concentration ( $\mathrm{pg} /$ $\mathrm{ml}$ ) between the two genders prior to the operation, postoperatively and in the controls are also shown. None of these comparisons resulted in significantly different serum concentrations of follistatin $(\alpha=0.001)$.

differences in their serum concentration $(\mathrm{pg} / \mathrm{ml})$ of follistatin (male preoperative: $1145 \pm 309 v s$. male postoperatively: $76 \pm 37$ and female preoperatively: $1114 \pm 237 v$ s. female postoperatively: $100 \pm 51)(\mathrm{P}<0.001)$ (Figure 2).

Similarly to the results above, gender didn't seem to have an effect on the serum concentration $(\mathrm{pg} / \mathrm{ml})$ of follistatin in the pre-operative controls either (male preoperative control $347.757 \pm 97.467$ vs. female preopative control $314.983 \pm 86.841)(\alpha=0.001)$ (Figure 2$)$. However, male and female controls had significantly different follistatin serum concentrations $(\mathrm{pg} / \mathrm{ml})$ when were compared to their equivalent preoperative patient samples (male preoperative control $348 \pm 97 v s$. male preoperative patient: $1145 \pm 309$; female preoperative control $315 \pm$ 87 vs. female preoperative patient: $1114 \pm 237)(\mathrm{P}<0.001)$ (Figure 2).

\section{Discussion}

Angiogenesis factors such as the VEGF and PDGF-BB have been previously proposed as potential candidate biomarkers to aid the management of malignant gliomas [30]-[35]. In this study follistatin serum concentrations have shown a significant correlation with the presence of malignant gliomas. More specifically, the average serum concentrations found in the healthy population (i.e. controls) for follistatin were $335( \pm 93) \mathrm{pg} / \mathrm{ml}$ whereas in the population with malignant tumour was $1133( \pm 279) \mathrm{pg} / \mathrm{ml}$ which later dropped down to $86( \pm 44) \mathrm{pg} / \mathrm{ml} \mathrm{after}$ the operation.

Interestingly, follistatin serum concentrations of the controls in this study were almost three times lower than the lowest concentrations reported in the literature $1060 \mathrm{pg} / \mathrm{ml}$ (range $1060-18490 \mathrm{pg} / \mathrm{ml}$ ) [23]. This finding was unanticipated as the controls were patients with degenerative spinal disease and there is evidence to support that serum follistatin concentrations reflect the severity of joint damage in osteoarthritis [36]. A possible explanation for this difference might be that these concentrations are not directly comparable as the methodology used to measure them is different. However, the Bio-Rad assay used in the present study has clearly identified differences in the follistatin concentrations measured between the preoperative and postoperative patients as well as the preoperative patients and controls.

This suggests that follistatin does indeed differ between healthy controls and tumour patients and that this methodology is a reliable way for measuring that. The Bio-Plex assay was proven to be a potent technique as it measures concentrations of multiple angiogenesis factors simultaneously from several samples within three to four hours. Furthermore, it is using a small quantity of sample, has low variability and high reproducibility making 
it suitable for use in clinical practice.

Patients affected by malignant gliomas in this study had higher pre-operative concentrations of follistatin than the healthy participants. Gliomas produce angiogenesis factors in response to hypoxia while promoting neoangiogenesis and growth [37]-[42]. Unlike the controls, the glioma patients in this present study were taking Dexamethasone in high dose $(16 \mathrm{mg} /$ day), which is widely known to down-regulate the production of VEGF, IL-6, follistatin and PDGF-BB [37]-[42]. Despite this, significant difference between the two groups was observed. One could speculate that if the patients were not taking Dexamethasone, the measured concentrations would be even higher.

To date, no studies have been reported in the literature comparing the angiogenesis factor concentrations between the patients affected by malignant glioma pre- and post-operatively. Angiogenesis factors that are related to the presence of the tumour would be expected to have their concentrations reduced following the tumour removal. In the present study, a significant reduction of the concentrations of follistatin was observed postoperatively. A decrease of more than $90 \%$ of the average value (from 1133 to $86 \mathrm{pg} / \mathrm{ml}$ ) for follistatin was noted. The effect of debulking surgery is one of the possible explanatory factors for this observation. As tumour cells constitutively produce angiogenesis factors, cell removal by the surgical operation would lead to a reduced production of these factors [30]-[35] [43]-[45].

Another potential cause for the drop of follistatin's concentration in postoperative patients could be the reduced hypoxic drive of the tumour following the operation. Hypoxia is known to stimulate angiogenesis factor production by tumour cells [30]. As surgery reduces the hypoxic area of the tumour, the stimulus for such production is also reduced.

Age did not influence the concentration of follistatin in any of the comparisons performed as all age groups tested yielded the same result. Moreover no significance was found between the age group comparisons within each dataset. No published reports on the effect of age on the angiogenesis factor concentrations of patients with malignant gliomas have been found. However, a study on healthy controls reported similar findings to the controls of our study in relation to age [46].

According to the results of this study, gender similarly to age did not influence the serum concentrations of follistatin tested in any of the datasets. As there are no previous reports for patients with malignant gliomas this finding is novel. However, studies on healthy individuals revealed that gender did not influence the follistatin concentrations [20].

This work demonstrates that follistatin is a suitable candidate biomarker for malignant gliomas. Such biomarker would aid clinicians with the diagnosis as well as management of patients during the course of their disease both in terms of monitoring response to treatment as well as early detection of disease recurrence. While angiogenesis factors such as VEGF and PDGF-BB have already been proposed for this role, their use has not been translated to clinical practice. This might be because they have low specificity for malignant gliomas, being present in almost all malignant and several pathological processes. These factors play a key role not only in the angiogenesis process that allows the tumour to grow, but also in the inflammatory processes during the course of benign disease. Furthermore, there is still a need to define clearly a method that will be widely validated and accepted for their measurement.

\section{Conclusion}

We are proposing follistatin as a novel biomarker for malignant gliomas. Its serum concentration differs significantly not only between preoperative controls and preoperative glioma patients, but also between patients preand post-operatively. Furthermore, this study investigates the role of gender and age between the two operative stages of the glioma patients. To our knowledge, this is the first study investigating the pre- $v s$. post-operative serum concentrations of follistatin in patients with malignant gliomas. As such, it contributes to a better understanding of this molecule and its role in this disease. Further studies with larger group of healthy controls and patients are expected to strengthen the case of the use of follistatin as biomarker for malignant gliomas while it will allow for novel ones to be discovered.

\section{Acknowledgements}

The authors would like to thank the Rosemere Cancer Foundation for the financial support and Anirban Bhaduri for his assistance with the data analysis. 


\section{Conflict of Interest/Disclosure}

The authors declare that they have no financial or other conflicts of interest in relation to this research and its publication.

\section{References}

[1] Kilpatrick, E.S. (2008) Haemoglobin A1c in the Diagnosis and Monitoring of Diabetes Mellitus. Journal of Clinical Pathology, 61, 977-982. http://www.ncbi.nlm.nih.gov/pubmed/18755721 http://dx.doi.org/10.1136/jcp.2007.054304

[2] Drevs, J. and Schneider, V. (2006) The Use of Vascular Biomarkers and Imaging Studies in the Early Clinical Development of Anti-Tumour Agents Targeting Angiogenesis. Journal of Internal Medicine, 260, 517-529. http://www.ncbi.nlm.nih.gov/pubmed/17116002 http://dx.doi.org/10.1111/j.1365-2796.2006.01727.x

[3] Falzarano, S.M., Ferro, M., Bollito, E., Klein, E.A., Carrieri, G. and Magi-Galluzzi, C. (2015) Novel Biomarkers and Genomic Tests in Prostate Cancer: A Critical Analysis. Minerva Urologica e Nefrologica, 67, 211-231. http://www.ncbi.nlm.nih.gov/pubmed/26054411

[4] Elzek, M.A. and Rodland, K.D. (2015) Proteomics of Ovarian Cancer: Functional Insights and Clinical Applications. Cancer and Metastasis Reviews, 34, 83-96. http://www.ncbi.nlm.nih.gov/pubmed/25736266 http://dx.doi.org/10.1007/s10555-014-9547-8

[5] Mustafa, G.M., Larry, D., Petersen, J.R. and Elferink, C.J. (2015) Targeted Proteomics for Biomarker Discovery and Validation of Hepatocellular Carcinoma in Hepatitis C Infected Patients. World Journal of Hepatology, 7, 1312-1324. http://www.ncbi.nlm.nih.gov/pubmed/26052377 http://dx.doi.org/10.4254/wjh.v7.i10.1312

[6] Louis, D.N., Ohgaki, H., Wiestler, O.D., Cavenee, W.K., Burger, P.C., Jouvet, A., Scheithauer, B.W. and Kleihues, P. (2007) The 2007 WHO Classification of Tumours of the Central Nervous System. Acta Neuropathologica, 114, 97-109. http://www.ncbi.nlm.nih.gov/pubmed/17618441 http://dx.doi.org/10.1007/s00401-007-0243-4

[7] Kleihues, P. and Ohgaki, H. (1999) Primary and Secondary Glioblastomas: From Concept to Clinical Diagnosis. Journal of Neuro-Oncology, 1, 44-51. http://www.ncbi.nlm.nih.gov/pubmed/11550301 http://dx.doi.org/10.1215/15228517-1-1-44

[8] Benjamin, R., Capparella, J. and Brown, A. (2003) Classification of Glioblastoma Multiforme in Adults by Molecular Genetics. The Cancer Journal, 9, 82-90. http://www.ncbi.nlm.nih.gov/pubmed/12784873 http://dx.doi.org/10.1097/00130404-200303000-00003

[9] Grant, R., Collie, D. and Counsell, C. (1996) The Incidence of Cerebral Glioma in the Working Population: A Forgotten Cancer? British Journal of Cancer, 73, 252-254. http://www.ncbi.nlm.nih.gov/pubmed/8546915 http://dx.doi.org/10.1038/bjc.1996.44

[10] http://seer.cancer.gov/statfacts/html/brain.html

[11] Vanan, M.I. and Eisenstat, D.D. (2014) Management of High-Grade Gliomas in the Pediatric Patient: Past, Present, and Future. Neuro-Oncology Practice, 1, 145-157. http://www.ncbi.nlm.nih.gov/pubmed/26034626

[12] Gilbert, M.R., Armstrong, T.S., Pope, W.B., van den Bent, M.J. and Wen, P.Y. (2014) Facing the Future of Brain Tumor Clinical Research. Clinical Cancer Research, 20, 5591-5600. http://www.ncbi.nlm.nih.gov/pubmed/25398842 http://dx.doi.org/10.1158/1078-0432.CCR-14-0835

[13] Ilhan-Mutlu, A., Wagner, L., Wöhrer, A., Furtner, J., Widhalm, G., Marosi, C. and Preusser, M. (2012) Plasma MicroRNA-21 Concentration May Be a Useful Biomarker in Glioblastoma Patients. Cancer Investigation, 30, 615-621. http://www.ncbi.nlm.nih.gov/pubmed/22891879

[14] Skog, J., Würdinger, T., van Rijn, S., Meijer, D.H., Gainche, L., Sena-Esteves, M., Curry Jr., W.T., Carter, B.S., Krichevsky, A.M. and Breakefield, X.O. (2008) Glioblastoma Microvesicles Transport RNA and Proteins That Promote Tumour Growth and Provide Diagnostic Biomarkers. Nature Cell Biology, 10, 1470-1476.

http://www.ncbi.nlm.nih.gov/pubmed/19011622 http://dx.doi.org/10.1038/ncb1800

[15] Chan, Q.K., Ngan, H.Y., Ip, P.P., Liu, V.W., Xue, W.C. and Cheung, A.N. (2009) Tumor Suppressor Effect of Follistatin-Like 1 in Ovarian and Endometrial Carcinogenesis: A Differential Expression and Functional Analysis. Carcinogenesis, 30, 114-121. http://www.ncbi.nlm.nih.gov/pubmed/18796737 http://dx.doi.org/10.1093/carcin/bgn215

[16] Chang, K.P., Kao, H.K., Liang, Y., Cheng, M.H., Chang, Y.L., Liu, S.C., Lin, Y.C., Ko, T.Y., Lee, Y.S., Tsai, C.L., 
Wang, T.H., Hao, S.P. and Tsai, C.N. (2010) Overexpression of Activin A in Oral Squamous Cell Carcinoma: Association with Poor Prognosis and Tumor Progression. Annals of Surgical Oncology, 17, 1945-1956. http://www.ncbi.nlm.nih.gov/pubmed/20309641 http://dx.doi.org/10.1245/s10434-010-0926-2

[17] Ogino, H., Yano, S., Kakiuchi, S., Muguruma, H., Ikuta, K., Hanibuchi, M., Uehara, H., Tsuchida, K., Sugino, H. and Sone, S. (2008) Follistatin Suppresses the Production of Experimental Multiple-Organ Metastasis by Small Cell Lung Cancer Cells in Natural Killer Cell-Depleted SCID Mice. Clinical Cancer Research, 14, 660-667.

http://www.ncbi.nlm.nih.gov/pubmed/18245525 http://dx.doi.org/10.1158/1078-0432.CCR-07-1221

[18] Zhao, W., Han, H.B. and Zhang, Z.Q. (2011) Suppression of Lung Cancer Cell Invasion and Metastasis by Connexin43 Involves the Secretion of Follistatin-Like 1 Mediated via Histone Acetylation. The International Journal of Biochemistry \& Cell Biology, 43, 1459-1468. http://www.ncbi.nlm.nih.gov/pubmed/21718795 http://dx.doi.org/10.1016/j.biocel.2011.06.009

[19] Sakamoto, Y., Shintani, Y., Harada, K., Abe, M., Shitsukawa, K. and Saito, S. (1996) Determination of Free Follistatin Levels in Sera of Normal Subjects and Patients with Various Diseases. European Journal of Endocrinology, 135, 345 351. http://www.ncbi.nlm.nih.gov/pubmed/8890727 http://dx.doi.org/10.1530/eje.0.1350345

[20] Evans, L.W., Muttukrishna, S. and Groome, N.P. (1998) Development, Validation and Application of an Ultra-Sensitive Two-Site Enzyme Immunoassay for Human Follistatin. Journal of Endocrinology, 156, 275-282.

http://www.ncbi.nlm.nih.gov/pubmed/9518873 http://dx.doi.org/10.1677/joe.0.1560275

[21] Kettel, L.M., De Paolo, L.V., Morales, A.J., Apter, D., Ling, N. and Yen, S.S. (1996) Circulating Levels of Follistatin from Puberty to Menopause. Fertility and Sterility, 65, 472-476. http://www.ncbi.nlm.nih.gov/pubmed/8774272

[22] Wakatsuki, M., Shintani, Y., Abe, M., Liu, Z.H., Shitsukawa, K. and Saito, S. (1996) Immunoradiometric Assay for Follistatin: Serum Immunoreactive Follistatin Levels in Normal Adults and Pregnant Women. Journal of Clinical Endocrinology \& Metabolism, 81, 630-634. http://www.ncbi.nlm.nih.gov/pubmed/8636280

[23] Widera, C., Horn-Wichmann, R., Kempf, T., Bethmann, K., Fiedler, B., Sharma, S., Lichtinghagen, R., Leitolf, H., Ivandic, B., Katus, H.A., Giannitsis, E. and Wollert, K.C. (2009) Circulating Concentrations of Follistatin-Like 1 in Healthy Individuals and Patients with Acute Coronary Syndrome as Assessed by an Immunoluminometric Sandwich Assay. Clinical Chemistry, 55, 1794-1800. http://www.ncbi.nlm.nih.gov/pubmed/19574466 http://dx.doi.org/10.1373/clinchem.2009.129411

[24] Laboratories, B.-R. (2010) Bio-Plex Pro Cytokine, Chemokine, and Growth Factors Assays. Instruction Manual.

[25] Kim, H.O., Kim, H.S., Youn, J.C., Shin, E.C. and Park, S. (2011) Serum Cytokine Profiles in Healthy Young and Elderly Population Assessed Using Multiplexed Bead-Based Immunoassays. Journal of Translational Medicine, 9, 113. http://www.ncbi.nlm.nih.gov/pubmed/21774806 http://dx.doi.org/10.1186/1479-5876-9-113

[26] http://www.r-project.org/

[27] http://dinmanlab.umd.edu/statistics/tutorial.html

[28] Shapiro, S.S. and Wilk, M.B. (1965) An Analysis of Variance Test for Normality (Complete Samples). Biometrika, 52 , 591-611. http://dx.doi.org/10.1093/biomet/52.3-4.591

[29] Student (1908) The Probable Error of a Mean. Biometrika, 6, 1-25. http://dx.doi.org/10.1093/biomet/6.1.1

[30] Carmeliet, P. (2003) Angiogenesis in Health and Disease. Nature Medicine, 9, 653-660. http://www.ncbi.nlm.nih.gov/pubmed/12778163 http://dx.doi.org/10.1038/nm0603-653

[31] Carmeliet, P. (2005) Angiogenesis in Life, Disease and Medicine. Nature, 438, 932-936. http://www.ncbi.nlm.nih.gov/pubmed/16355210 http://dx.doi.org/10.1038/nature04478

[32] Folkman, J. (2007) Angiogenesis: An Organizing Principle for Drug Discovery? Nature Reviews Drug Discovery, 6, 273-286. http://www.ncbi.nlm.nih.gov/pubmed/17396134 http://dx.doi.org/10.1038/nrd2115

[33] Gratzl, M. and Dahl, G. (1976) $\mathrm{Ca}^{2+}$-Induced Fusion of Golgi-Derived Secretory Vesicles Isolated from Rat Liver. FEBS Letters, 62, 142-145. http://www.ncbi.nlm.nih.gov/pubmed/1253976 http://dx.doi.org/10.1016/0014-5793(76)80038-5

[34] Wesseling, P., Ruiter, D.J. and Burger, P.C. (1997) Angiogenesis in Brain Tumors; Pathobiological and Clinical Aspects. Journal of Neuro-Oncology, 32, 253-265. http://www.ncbi.nlm.nih.gov/pubmed/9049887 
http://dx.doi.org/10.1023/A:1005746320099

[35] Fischer, I., Gagner, J.P., Law, M., Newcomb, E.W. and Zagzag, D. (2005) Angiogenesis in Gliomas: Biology and Molecular Pathophysiology. Brain Pathology, 15, 297-310. http://www.ncbi.nlm.nih.gov/pubmed/16389942 http://dx.doi.org/10.1111/j.1750-3639.2005.tb00115.x

[36] Mobasheri, A. (2012) Osteoarthritis Year 2012 in Review: Biomarkers. Osteoarthritis Cartilage, 20, 1451-1464. http://www.ncbi.nlm.nih.gov/pubmed/22842200

[37] Yano, A., Fujii, Y., Iwai, A., Kageyama, Y. and Kihara, K. (2006) Glucocorticoids Suppress Tumor Angiogenesis and in Vivo Growth of Prostate Cancer Cells. Clinical Cancer Research, 12, 3003-3009. http://www.ncbi.nlm.nih.gov/pubmed/16707595 http://dx.doi.org/10.1158/1078-0432.CCR-05-2085

[38] Greenberger, S., Boscolo, E., Adini, I., Mulliken, J.B. and Bischoff, J. (2010) Corticosteroid Suppression of VEGF-A in Infantile Hemangioma-Derived Stem Cells. The New England Journal of Medicine, 362, 1005-1013. http://www.ncbi.nlm.nih.gov/pubmed/20237346 http://dx.doi.org/10.1056/NEJMoa0903036

[39] Kawakami, S., Fujii, Y. and Winters, S.J. (2001) Follistatin Production by Skin Fibroblasts and Its Regulation by Dexamethasone. Molecular and Cellular Endocrinology, 172, 157-167. http://www.ncbi.nlm.nih.gov/pubmed/11165049 http://dx.doi.org/10.1016/S0303-7207(00)00371-3

[40] Machein, M.R., Kullmer, J., Ronicke, V., Machein, U., Krieg, M., Damert, A., Breier, G., Risau, W. and Plate, K.H. (1999) Differential Downregulation of Vascular Endothelial Growth Factor by Dexamethasone in Normoxic and Hypoxic Rat Glioma Cells. Neuropathology and Applied Neurobiology, 25, 104-112.

http://www.ncbi.nlm.nih.gov/pubmed/10215998 http://dx.doi.org/10.1046/j.1365-2990.1999.00166.x

[41] Nauck, M., Karakiulakis, G., Perruchoud, A.P., Papakonstantinou, E. and Roth, M. (1998) Corticosteroids Inhibit the Expression of the Vascular Endothelial Growth Factor Gene in Human Vascular Smooth Muscle Cells. European Journal of Pharmacology, 341, 309-315. http://www.ncbi.nlm.nih.gov/pubmed/9543253 http://dx.doi.org/10.1016/S0014-2999(97)01464-7

[42] Xu, W., Guo, T., Zhang, Y., Jiang, X., Zhang, Y., Zen, K., Yu, B. and Zhang, C.Y. (2011) The Inhibitory Effect of Dexamethasone on Platelet-Derived Growth Factor-Induced Vascular Smooth Muscle Cell Migration through UpRegulating PGC-1alpha Expression. Experimental Cell Research, 317, 1083-1092.

http://www.ncbi.nlm.nih.gov/pubmed/20955697 http://dx.doi.org/10.1016/j.yexcr.2010.10.006

[43] Bergers, G. and Benjamin, L.E. (2003) Tumorigenesis and the Angiogenic Switch. Nature Reviews Cancer, 3, 401-410. http://www.ncbi.nlm.nih.gov/pubmed/12778130 http://dx.doi.org/10.1038/nrc1093

[44] Berse, B., Brown, L.F., Van de Water, L., Dvorak, H.F. and Senger, D.R. (1992) Vascular Permeability Factor (Vascular Endothelial Growth Factor) Gene Is Expressed Differentially in Normal Tissues, Macrophages, and Tumors. Molecular Biology of the Cell, 3, 211-220. http://www.ncbi.nlm.nih.gov/pubmed/1550962 http://dx.doi.org/10.1091/mbc.3.2.211

[45] Lee, J.K., Hong, Y.J., Han, C.J., Hwang, D.Y. and Hong, S.I. (2000) Clinical Usefulness of Serum and Plasma Vascular Endothelial Growth Factor in Cancer Patients: Which Is the Optimal Specimen? International Journal of Oncology, 17, 149-152. http://www.ncbi.nlm.nih.gov/pubmed/10853032

[46] Lieb, W., Safa, R., Benjamin, E.J., Xanthakis, V., Yin, X., Sullivan, L.M., Larson, M.G., Smith, H.M., Vita, J.A., Mitchell, G.F., Sawyer, D.B. and Vasan, R.S. (2009) Vascular Endothelial Growth Factor, Its Soluble Receptor, and Hepatocyte Growth Factor: Clinical and Genetic Correlates and Association with Vascular Function. European Heart Journal, 30, 1121-1127. http://www.ncbi.nlm.nih.gov/pubmed/19223316 http://dx.doi.org/10.1093/eurheartj/ehp007 